\title{
Las ideas que habitan el aire. Artistas en diálogo con Las tres mitades de Ino Moxo ${ }^{1}$
}

\section{The ideas that inhabit the air. Artists in dialogue with "The three halves of Ino Moxo"}

Giuliana Vidarte ${ }^{2}$

Pontificia Universidad Católica del Perú

\section{Resumen}

Los objetivos de este ensayo son analizar cómo el escritor César Calvo en su novela "Las tres mitades de Ino Moxo y otros brujos de la Amazonía” (1981) establece relaciones con otras artes - como la fotografía, la pintura o la música- y, a su vez, revisar una serie de proyectos que han ido surgiendo como "ideas que habitan el aire", desplegándose posterior-

1 Este proyecto de investigación se presentó bajo la forma de una exposición en la Sala Miraflores del Instituto Cultural Peruano Norteamericano de la ciudad de Lima del 2 de agosto al 2 de setiembre de 2018. La exposición incluyó el trabajo de Armando Andrade Tudela, Graciela Arias, César Calvo de Araújo, Harry Chávez, Nora de Izcue, Augusto Falconi, Francesco Mariotti, Nancy La Rosa, Rocio Rodrigo, Jesús Ruiz Durand y Yando. El proyecto fue parte de las actividades de Bufeo. Amazonía+Arte.

2 Curadora de Bufeo. Amazonía+Arte. Contacto: gvidarte.b@gmail.com 
mente, al recuperar la obra como referente en el siglo XXI. La intención del análisis es reafirmar el valor de la publicación como un aporte clave para los diálogos entre la literatura y las artes visuales, en el arte peruano. Y, finalmente, también proponer que la novela de César Calvo - por su forma de comprender y afirmar las relaciones entre diversos medios y soportes artísticos - es muy importante para el surgimiento y desarrollo del lenguaje contemporáneo de las artes visuales en la Amazonía peruana.

Para esto, la argumentación se encuentra dividida en cuatro apartados. En el primero, se revisan casos de obras de artistas que aparecen en la narración de Calvo como personajes y que son destacadas figuras de la tradición pictórica amazónica del siglo XX. En un segundo momento, se analizan diversos documentos - fotografías, audios, cartas, serigrafías, entre otros - que dan cuenta del intercambio entre el escritor y otros artistas que lo acompañaron durante la creación de la novela. En un nivel distinto de relación con la obra, el tercer apartado se concentra en destacar a otros creadores que también llevaron a cabo investigaciones sobre las sesiones de la ayahuasca y el conocimiento compartido a través de estas prácticas, en paralelo al trabajo de Calvo. Finalmente, en el último apartado se revisan algunas de las propuestas de reinterpretación que desde las artes visuales se han llevado a cabo

14 en el siglo XXI. Con estos cuatro enfoques, se busca representar, desde diferentes perspectivas, los fructíferos diálogos que se han establecido a partir de la novela, la que, además, acerca a los lectores a una forma particular de comprender y valorar las tradiciones de los pueblos originarios de la Amazonía.

Palabras clave: César Calvo, Ino Moxo, Francesco Mariotti, Nora de Izcue, arte amazónico, arte contemporáneo. 


\section{Abstract}

This essay seeks to analyze how Cesar Calvo, in his novel "The Three Halves of Ino Moxo: Teachings of the Wizard of the Upper Amazon" (1981) establishes a dialogue with other arts photography, music, painting - and to review the projects that have gradually emerged as "ideas in the air", eventually unfolding as the author's work is recovered as a 21 st century milestone. The analysis aims also to consolidate the piece's value as a key contribution to the dialogue between literature and visual arts in Peru. Finally, the essay proposes that César Calvo's novel -in how it understands and affirms the dialogues between diverse artistic forms and media - is fundamental to the development of contemporary visual arts language in the Peruvian Amazon.

For this purpose, the paper is divided into four sections. The first reviews the works of prominent artists of the 20th century Amazon pictorial tradition, who appear in Calvo's narrative as fictional characters. The second section analyzes various documents - photographs, audios, letters, silkscreens, among others- accounting for the exchange between the writer and other artists that accompanied him throughout the creation of the novel. At a different level in terms of how it relates to the piece, the third part highlights other creators who, parallel to Calvo's work, have also researched Ayahuasca sessions and the shared knowledge these processes bring about. Finally, the last section reviews some reinterpretation proposals that have come up in the 21 st century in the visual arts. Altogether, these four approaches seek to represent, from different perspectives, the fruitful dialogues that have stemmed from the novel, a piece that brings us ever closer to a particular way of understanding and appreciating the traditions of indigenous Amazonian communities. 
Key words: Cesar Calvo, Ino Moxo, Francesco Mariotti, Nora de Izcue, Amazonian Art, Contemporary Art.

"Los pensamientos de la gente buena viven en el aire, se alojan en el aire, lo mismo que nosotros en nuestra casa. Antes de ser llevados a los libros, al sólo ser pensados y aunque nunca se escriban, ya viven en el aire. El maestro Ino Moxo me reveló que las ideas se graban mejor sobre el aire que sobre los cuadernos" (César Calvo, "Las tres mitades de Ino Moxo y otros brujos de la Amazonía").

En la grabación de una entrevista llevada a cabo por César Calvo a Vinícius de Moraes (1913-1980) en 1979, el compositor brasileño le consulta sobre qué es lo que está escribiendo y le pregunta si se trata de un romance. Calvo le responde que se encuentra trabajando sobre "precisamente lo que vivió en la Amazonía con los médicos brujos". ${ }^{3}$ El escritor peruano se refiere, en este caso, a su novela "Las tres mitades de Ino Moxo y otros brujos de la Amazonía” (1981). Al parecer su intención es destacar el valor de su propia experiencia de investigación en la Amazonía peruana como punto de partida para su novela, para pensarla como una crónica, nutrida de las historias y mitos que pudo recuperar en este proceso, iniciado a mediados de los años setenta. Esto anticipa la forma en que creará personajes, parte de su narración, que evocan a figuras clave para las artes y la cultura amazónica del siglo XX en el Perú, como pintores, músicos y poetas de la región. Y, además, construirá ciertas imágenes de la novela basadas en representaciones pictóricas de artistas muy destacados de la tradición paisajística regional.

3 Esta grabación es parte del archivo Mariotti-Luy, actualmente, en custodia en el Museo de Arte de Lima. 
El propio Calvo explica en una entrevista, llevada a cabo por Ricardo González Vigil en 1982, que el proceso de trabajo para la novela se inició con un reportaje sobre Manuel Córdova - el chamán mestizo amawaka Ino Moxo (Pantera Negra) - que vivía en ese momento en Iquitos y curaba gratuitamente al público (320-321). Además, el escritor comenta que pensaba inicialmente colocar el título de "Crónica de Ino Moxo" a la publicación. Finalmente, su obra toma la forma de una exploración en las visiones de la medicina de la ayahuasca y el posterior regreso abrupto al reportaje en Iquitos (324) y se construye también como un "alegato en favor de los pueblos amazónicos” (Elguera, 2019). La novela, entonces, surge teniendo como eje a la figura de Ino Moxo, quien es acompañado de otros personajes que representan, desde diferentes enfoques, el conocimiento y la cultura que se gesta desde la Amazonía.

Para esto, Calvo reúne en esta publicación diversos géneros literarios y narraciones desde perspectivas muy distintas, construyendo un discurso híbrido. El investigador Robert Baca se pregunta, por ejemplo: “¿por qué la obra se presenta como una imagen caleidoscópica que proyecta siempre una polifonía de voces y registros sociohistóricos en conflicto?" (35). El propio Baca esboza la hipótesis de conexión de los discursos heterógeneos que conviven en la novela con la intención de acercarse a las problemáticas de un contexto también plural: "Esta continuidad de interioridades comienza con el viaje individual del protagonista y termina con la visión de discontinuidades de diferentes periodos de violencia histórica de la Amazonía. Entonces, estas visiones variadas sobre el Perú esbozarían las fisicalidades discontinuas de un país plural y conflictivo" (35). 
A su vez, el crítico italiano Antonio Melis plantea una lectura de la novela que resalta el valor de la Amazonía peruana también como un espacio muy productivo para pensar las diversas problemáticas que aquejan al país en su conjunto. Así, Melis propone los siguiente: "El mundo de la selva olvidada y marginada se transforma así [en la novela] en un observatorio inédito y privilegiado, imprescindible para comprender el todo del país, todo el país. Justamente porque se trata de un caso límite, de una forma extremada de opresión y negación, es posible reconstruir a partir de allí todas las mitades del Perú” (12).

Otro elemento clave de la narración es la representación de la problemática de la explotación de los ciudadanos indígenas, durante el "boom" de extracción de las gomas, a inicios del siglo XX. Calvo explica como el viejo Ximu propone el rapto del niño Manuel Córdova pues "quería preservar a su nación de las masacres organizadas por los caucheros blancos" (González Vigil, 320). Él, por su condición mestiza, podría tener acceso a la compra de armas para la defensa del pueblo amawaka. El investigador Christian Elguera lo explica de esta manera: "Lo que busca Ino Moxo es que a través de César Soriano el público conozca y comprenda las consecuencias fatales de una modernidad sanguinaria, por esto se precisa: 'Y los caucheros virakochas necesitaban de ese caucho, dicen 18 para el progreso de la Patria. Así, andan diciendo hasta ahorita. En nombre del progreso fue que nos despojaban y nos baleaban'” (222).

De otro lado, la novela fue destacada por la crítica por su representación del castellano amazónico. El propio Calvo considera que en su narración ha dejado "que la Selva hable, o que la Selva a través de sus gentes hable" (González Vigil, 
324). Ricardo González Vigil en un texto publicado en el suplemento Dominical el 10 de enero de 1982 destaca entre los "aciertos expresivos" de Ino Moxo "la recreación del habla oral en un estupendo intento de insertar el aire del idioma campa en castellano, afín a la 'quechuización del español' labrada por Arguedas; el montaje de tiempos, espacios, visiones, identidades de los personajes, adecuado para instalar una estructura profundamente mítica y mágica en la que lo no narrado no tiene comienzo ni fin, ni se sujeta a la lógica de Occidente" (318).

En "Las tres mitades de Ino Moxo y otros brujos de la Amazonía” (1981) el escritor peruano César Calvo Soriano (1940-2000), a través de narraciones de la mitología amazónica, visiones de diversos tiempos y culturas - como las tradiciones indígenas o la afroperuana- y el viaje en búsqueda del maestro Ino Moxo (Pantera Negra), delinea la posibilidad de una mirada integral del Perú. Desde su propuesta, el ritual y las visiones de la ayahuasca nos permiten reconocer y compartir el conocimiento de las más diversas culturas del país. Los saberes de estas culturas se encuentran "grabados" en el aire —que también es de todos- y desde ahí ordenan nuestras vidas y "nos nutren y nos dan aliento".

En las últimas décadas, esta novela se ha convertido en un material sumamente influyente y fuente de diversas reinterpretaciones llevadas a cabo por artistas contemporáneos. Se trata de uno de los referentes principales de muchos creadores que se han volcado a trabajar sobre el conocimiento, cosmovisión y problemáticas de la Amazonía peruana. Es, a su vez, un elemento clave para comprender el desarrollo de las artes visuales contemporáneas amazónicas. En los años ochenta y noventa, esta obra de Calvo, junto a los proyec- 
tos de otros artistas — como Nora de Izcue (Lima, 1934), Francesco Mariotti (Berna, Suiza, 1943) o Yando (Pucallpa, 1940) — son hitos del surgimiento de un lenguaje contemporáneo para las artes en la región. Las propuestas de estos creadores nos muestran a una generación que, desde diversos medios y lenguajes, y con una investigación basada en el conocimiento de la medicina de la ayahuasca, renuevan las prácticas artísticas amazónicas.

Los objetivos del presente ensayo son analizar cómo el escritor César Calvo decide a través de su novela, y durante el proceso de creación de esta, establecer relaciones con otras artes - como la fotografía, la pintura o la música-y, a su vez, revisar una serie de proyectos que han ido surgiendo como “ideas que habitan el aire”, desplegándose posteriormente, al recuperar la obra como referente en el siglo XXI. La intención del análisis es reafirmar el valor de la publicación como un aporte clave para los diálogos entre la literatura y las artes visuales, en el arte peruano. Y, finalmente, también proponer que la novela de César Calvo - por su forma de comprender y afirmar las relaciones entre diversos medios y soportes artísticos- es muy importante para el surgimiento y desarrollo del lenguaje contemporáneo de las artes visuales en la Amazonía peruana. Para esto, la argumentación se encuentra dividida en cuatro apartados. En el primero, se revisarán casos

20 de obras de artistas que aparecen en la narración de Calvo como personajes y que son destacadas figuras de la tradición pictórica amazónica del siglo XX. En un segundo momento, se analizarán diversos documentos — fotografías, audios, cartas, serigrafías, entre otros - que dan cuenta del intercambio entre el escritor y otros artistas que lo acompañaron durante la creación de la novela. 
En un nivel distinto de relación con la obra, el tercer apartado se concentra en destacar a otros creadores que también llevaron a cabo investigaciones sobre las sesiones de la ayahuasca y el conocimiento compartido a través de estas prácticas, en paralelo al trabajo de Calvo. Finalmente, en el último apartado se revisarán algunas de las propuestas de reinterpretación que desde las artes visuales se han llevado a cabo en el siglo XXI. Con estos cuatro enfoques, se busca representar, desde diferentes perspectivas, los fructíferos diálogos que se han establecido a partir de la novela, la que, además, acerca a los lectores a una forma particular de comprender y valorar las tradiciones de los pueblos originarios de la Amazonía.

\section{"Los pensamientos de la gente buena viven en el aire"}

A lo largo de su novela, Calvo hace mención de destacados artistas, poetas o músicos de la Amazonía. Ellos pasan a ser personajes que aparecen en las visiones, son protagonistas de las narraciones, enuncian los mitos, o incluso sus propias obras - esculturas, pinturas o canciones- son descritas como parte de los espacios y atmósferas creados por el autor. De esta manera, es posible afirmar que las imágenes de la novela se construyen en estrecha relación con las prácticas artísticas amazónicas de la época de su publicación. Al incluir estas obras y sus creadores, como parte de la narración, el autor está reconociendo el valor de un imaginario amazónico que se ha construido a través de las artes plásticas. A su vez, el au-

4 Los títulos de cada uno de los apartados corresponden a citas tomadas de la novela de Calvo y evocan la posibilidad de transmitir o compartir estas "ideas que habitan el aire" en diversos momentos de la historia de la publicación: creación, difusión y reinterpretación contemporánea. 
tor despliega una propuesta mucho más contemporánea que explora la posibilidad de reunir diversos lenguajes artísticos en un mismo proyecto.

Dentro de este grupo de artífices destaca la figura del padre del escritor: el pintor amazónico César Calvo de Araújo (Yurimaguas, 1914 - Lima, 1970). Este creador es reconocido, actualmente, con un referente muy importante para el desarrollo pictórico de la región. Los investigadores Alfredo Villar y Christian Bendayán proponen que "Todo pintor amazónico está en eterna deuda con sus descubrimientos, técnicas y finas observaciones de la gente y el paisaje de la selva" $(2015,56)$. De otro lado, Mónica Solórzano describe la vigencia de la impronta de Calvo de Araújo en la "figuración de contenido social así como la afirmación e identificación regionalista” (22) de las propuestas de arte amazónico más actuales. Este pintor del siglo XX representa una renovación del imaginario sobre la región desde la pintura, con su obra se enfrenta a los mitos que definían a la Amazonía como el "infierno verde" o "el pueblo sin tiempo", buscando generar una pintura constituida sobre un conocimiento más certero de la flora, fauna y realidad social de esta región (Vidarte 2016, 91).

Calvo de Araújo es mencionado como personaje en diversos 22 pasajes de la novela, siempre resaltando que es un conocedor de las tradiciones y la historia amazónica. Por ejemplo, César Soriano describe lo siguiente en el sexto capítulo de la primera parte: "Esta es la casa que hace veinte años hospedó mis vacaciones escolares gracias a una misiva de mi tío César Calvo de Araújo, el Pintor de la Selva. El viento no ha pasado. Son las mismas ventanas de madera tantas veces pintada, persianas que mi tío supo apartar con dedos de aguarrás y 
tabaco y pinceles [...]" (59). Además, los propios personajes reconocen paisajes amazónicos que ven por primera vez, pues ya los habían contemplado previamente en los cuadros del pintor: "Detrás de aquellas alas reconozco el paisaje, pero no estuve nunca antes aquí, lo he mirado en un cuadro, el sitio exacto, los colores puntuales, la misma luz cantando entre las púas del enredo de paka, no hay duda que el pintor Calvo de Araújo esbozó ese óleo desde aquí, su memoria sentada sobre este árbol, yo lo miré pintarlo años atrás en Lima” (67). De esta manera, los cuadros son elementos que anticipan las visiones de los personajes y el escritor destaca el conocimiento preciso del pintor de la naturaleza amazónica al delinear la posibilidad de confundir o mezclar el recuerdo de la pintura con la experiencia del paisaje real.

Otro artista que también es mencionado como un personaje en la novela - pero que pertenece a una generación diferente a la de Calvo de Araújo- es Yando, hijo, además, del chamán Hildebrando Ríos. Él estudió en la Escuela de Bellas Artes de Lima, luego llevó a cabo exposiciones en Iquitos y Lima antes de instalarse en los EEUU en 1971. Actualmente, ha vuelto a la ciudad de Pucallpa para continuar con sus proyectos artísticos relacionados con la Amazonía peruana. Yando inicia su carrera con propuestas muy cercanas a la tradición paisajística regional, luego sus trabajos se acercan a una cierta abstracción incluyendo en sus composiciones elementos que se alejan de la flora y fauna más tradicional, y que parecen más cercanos a experiencias oníricas. Su obra ha sido definida como "un universo donde el exterior y el interior, la alucinación y la realidad se han vuelto uno solo" (Bendayán y Villar 2013, 31), relacionando su pintura con las visiones de la medicina de la ayahuasca. "Su dibujo desarrolla fugitivas líneas laberínticas que van más allá de la representación y 
donde las visiones se difractan en múltiples niveles de realidad [...]" (Bendayán y Villar 2013, 31).

En la novela, el personaje Yando Ríos es quien contagia a César - uno de los protagonistas de la narración- "su pasión por la magia" (Calvo, 99) y juntos frecuentan al padre de Yando para aprender sobre el conocimiento de "la soga de los muertos", y así logran reconocer la jerarquía que aún perdura entre los "brujos selváticos" (Calvo, 99). Pero, más allá de la construcción del artista como personaje la propuesta de su obra se puede relacionar con ciertos conceptos desarrollados por Calvo en su novela. En el libro se presenta, por ejemplo, una imagen de la Amazonía como un espacio polifónico que es imposible de abarcar, con una narración, por su complejidad. A su vez, en el proemio Calvo describe un espacio en el que suenan los animales - mencionando a una larga lista de ellos- pero también explica que se trata de un lugar donde "Suenan también las plantas, los vegetales [...]" (27). Esta posibilidad de oír, al mismo tiempo, a plantas y animales recupera, también, cierta mirada sobre la inteligencia de la naturaleza y saberes de las comunidades amazónicas que proponen que estos seres tienen la capacidad de comunicarse y buscan compartir su conocimiento. A esto se le pueden sumar otras ideas para enriquecer la interpretación, como pensar por ejemplo cómo en las narraciones de la mitología

24 de la región los humanos pueden tomar la forma de plantas y animales o viceversa, además, de tener en cuenta que muchas de estas especies cuentan con un "dueño" protector. De esta manera, las conexiones entre lo humano y animal, y la vastedad de la naturaleza en el territorio amazónico se encuentran muy presentes en la novela de Calvo: "Y más que nada suenan los pasos de los animales que uno ha sido antes de humano, los pasos de las piedras y los vegetales y las cosas 
que cada humano ha sido. Y también lo que uno ha escuchado antes, todo eso suena en la noche de la selva" (29).

En los dibujos de Yando se pueden encontrar ciertas coincidencias con el acercamiento propuesto por Calvo. Mientras Calvo en su proemio busca describir todo lo que "suena" en la Selva - estrategia que más bien destaca la vastedad del territorio y la imposibilidad de representación total- Yando en sus dibujos busca también transmitir imágenes que sugieren la amplitud de elementos con los que uno se enfrenta en la experiencia en el territorio amazónico. Por ejemplo, en su tapir o sachavaca de 1991 (fig. 1) - hecho en tinta sobre papel- el artista marca como tatuajes en la piel del animal, líneas que componen imágenes de plantas y animales amazónicos, además de astros y elementos cósmicos, o edificios y ciudades, todos interconectados en una misma ilustración. También en uno de sus dibujos de 1991, titulado Vía Láctea Manatí, representa un manatí en cuya piel se encuentran constelaciones, astros, acompañados de animales míticos amazónicos - como el otorongo o la serpiente- y edificaciones tradicionales ribereñas de la región, así como edificios de urbes más contemporáneas.

Así, los dibujos de Yando construyen una mirada sobre la Amazonía como un espacio de diálogo e intercambio entre diversos elementos, además, de un ámbito de fluidez entre estas conexiones y convivencia armónica de las representaciones. En una entrevista ${ }^{5}$ ante la pregunta sobre por qué construye sus composiciones a través de la cohesión de figuras y elementos tan diversos, Yando responde de la siguiente

5 Esta entrevista fue llevada a cabo por Christian Bendayán en mayo de 2018 en la ciudad de Pucallpa. 
manera: "la respuesta es simple y solo hay una: anda a la Selva”. De esta forma, alude a esta intención de capturar la esencia de la naturaleza amazónica como polifónica y polimorfa, objetivo que se conecta con el discurso desplegado en el proemio de Calvo. Además, en otra entrevista ${ }^{6}-$ de julio de 2018- Yando explica con mayor detalle cómo construye su mirada sobre la naturaleza amazónica al plantear que "cuando uno entra a la selva está rodeado de todo [...] [lo que] es como estar en ninguna parte" y esa experiencia particular es la que busca recuperar en sus proyectos. A su vez, esta representación de lo tangible es entendida por el artista también como un camino de introspección: "cuando alguien ve mi pintura, lo confronto a que mire dentro de sí mismo".

La novela no solo establece, en este sentido, diálogos con las artes visuales, sino también con la música o la poesía. Así, Calvo también alude a otros artistas amazónicos como el músico Raúl Vásquez, quien es descrito como el juglar de la Selva y cuyas composiciones son recuperadas como parte de la narración de Calvo. Además, el personaje del músico, en la novela, cuenta que aprendió del chamán Ino Moxo una serie de canciones mágicas, "icaros y otras bubinzanas" (191). De la misma manera, se describen las esculturas de Agustín Rivas y se incluye como otro personaje muy importante a don Javier, que alude a la figura del poeta amazónico Javier Dávila

26 Durand. Así, la narración de la novela se nutre de este imaginario recuperando las expresiones del arte amazónico, lo que contribuye en una defensa de la identidad regional de estas artes. En este primer apartado, se ha planteado un acercamiento a esta propuesta desde el caso específico de dos artis-

6 Yo llevé a cabo esta entrevista en la ciudad de Pucallpa. 
tas amazónicos. Primero, Calvo de Araújo, para pensar en un imaginario artístico, centrado en el paisaje, que influencia en la construcción de las imágenes que evoca la novela. Y luego, en la obra de Yando, para analizar un enfoque compartido sobre las posibilidades de la representación amazónica peruana, a través del arte, en la segunda parte del siglo XX.

\section{"Leer en el aire"}

Durante la creación de "Las tres mitades de Ino Moxo y otros brujos de la Amazonía”, Calvo establece relaciones de diálogo e intercambio con otros artistas de su generación. Por ejemplo, le propone a Francesco Mariotti que desarrolle una serie de grabados para ilustrar la novela. De otro lado, la carátula de la primera edición de la novela es un trabajo de diseño, también en conjunto, entre Calvo y Mariotti. El primero había hecho ya el dibujo preliminar que se ubicaría en el centro de la cubierta y le pidió a Mariotti imprimirlo en una serigrafía. Ellos deciden entonces hacer la impresión no sobre un papel sino sobre una corteza natural. De esta manera, se construye la imagen de esta portada. Calvo también, decide incluir en una parte de la publicación, diversas fotografías llevadas a cabo durante su viaje de investigación. Entre ellas destacan las de Augusto Falconi (Yurimaguas, 1948), quien retrata al chamán Manuel Córdova (Ino Moxo) junto a César Calvo.

César Calvo y Francesco Mariotti se conocen en Cusco en 1972. Cuando Mariotti trabajaba para el SINAMOS, el escritor llega a la ciudad para desarrollar actividades con la misma oficina y su grupo cultural que se llamaba "Javier Heraud”. Ellos establecen una relación de amistad muy cerca- 
na. Cuenta el artista lo siguiente: "Él me decía ayumpari, éramos más que hermanos. Gran parte de la novela [...] la escribió en nuestra casa en Chaclacayo. Luego, César me entregó el manuscrito y me pidió que haga unas ilustraciones (Bendayán y Vidarte 2017, 77). El propio Calvo explica, en el vocabulario que acompańa la narración de la novela, el significado del término ayumpari:

"Asháninca que acepta o establece un intercambio de regalos con otro miembro de su nación. Los asháninca confieren a esta costumbre ancestral, categoría de institución sagrada. No se trata de dar para recibir. Se trata de respirar. La vida está en el aire, no es de nadie, es de todos. Si merezco y consigo ser tu ayumpari, al regalarte algo, flechas, manojos de sal, pasta de achiote, no te estoy dando la vida: me la estoy devolviendo [...]" (309).

En una carta enviada por Calvo a Mariotti el 18 de mayo de 1981 - durante el proceso de edición de la novela y creación de los grabados- este se dirige a su amigo con el encabezado de "mi querido ayumpari" y, además, se refiere a la novela como "nuestro libro" asumiendo una creación colectiva.

Un grupo de documentos, que incluyen audios y cartas, que se conservan como parte del archivo Mariotti Luy ${ }^{7}$ dan cuenta del diálogo creativo que se establece entre ambos artífices, durante el proceso de desarrollo de la novela y las ilustraciones que la acompañan. Por ejemplo, en una grabación enviada por Calvo - a través de María Luy- a Mariotti, que se encontraba en Suiza, este le indica lo siguiente al artista:

7 Como ya se había mencionado este archivo se encuentra, actualmente, en custodia en el Museo de Arte de Lima. 
"no hay apuro por los grabados, ojalá que no te capture la civilización Suicida (osea de Suiza) y hagas algo que tenga que ver con lo que tú eres en tu esencia misma, osea que tengas más que ver con la Selva que con la modernidad del artificio que conlleva el arte. Preferiría que regresaras a tu época de figurativismo [...] y que los grabados no contradigan con la esencia del libro que es defender una cultura nativa [...] sino que los grabados se integren a esa cultura e integren al espectador para que entienda mejor no solo el libro sino lo que estamos tratando de restituir, lo que Antonio Melis llama la 'reivindicación de la identidad de una cultura”.

En estas afirmaciones del escritor es posible reconocer su intención de lograr que los grabados tengan una conexión con la identidad amazónica y sirvan también para el objetivo de la novela que, desde su voz, es la defensa del valor de la cultura de la Amazonía.

En este envío, Calvo también graba la narración, con su propia voz, de la descripción del manguaré ${ }^{8}$ que forma parte del vocabulario que acompaña la novela. Además, incluye la lectura del mito de Kaametza y Narowé, haciendo mucho hincapié en el valor que le da al instrumento tradicional, ${ }^{9}$ en

8 "Instrumento de percusión hecho de un tronco resecado y hueco. Los nativos le dan vida y sonido golpeando su corteza con un palo envuelto en trapos embreados. El manguaré es tocado de diversas maneras, según códigos rítmicos cuyo conocimiento es exclusivo del jefe brujo y de sus allegados, generalmente para enviar mensajes y advertir peligros, otras veces para convocarse con intención guerrera, otras para invocar a las ánimas, o para sacudir a los espíritus de los antepasados a punto de dormirse [...]" (Calvo, 325).

9 "Cuando Narowé despertó sin Kaametza, el día se separó de la noche. Y Narowé conoció la soledad. [...] Y de un solo flechazo derribó a la luna, a la primera luna que tuvo nuestro mundo. [...] La luna entonces era un 
relación con el mito amazónico y el origen del mundo. Mariotti, después de haber recibido este material, le escribe a su esposa en una carta del 7 de mayo de 1981 y describe su proceso de creación de los grabados, casi como un ritual: "El libro del flaco es genial [...] el loco pinta cuando escribe y entonces cuando estoy súper cruzado y que yo ya no soy yo, entonces allí debe ser que el Soriano dentro de uno lee en el aire, como Don Hildebrando y me salen así como a tartamudo unos dibujos que espero le gusten a César". El artista afirma entonces que se siente llevado por una fuerza mayor, "el Soriano dentro de él” —el escritor dentro de él—. Además, agrega que cuando termina de hacer los grabados le duelen "todas las entrañas" como si hubieran tomado una parte de él.

En una entrevista, ${ }^{10}$ llevada a cabo en abril de 2018, Mariotti explica que Calvo esperaba tal vez veinte o cuarenta grabados, pero que él hace finalmente seis. Luego, de las primeras comunicaciones, durante el proceso en sí, él ya no hace ninguna consulta al escritor y desarrolla las obras de una manera bastante distinta a su proceso de trabajo convencional: "Yo nunca había hecho algo así, no es mi escritura, pero sí fue como una alucinación. Yo estaba solo [...] me había traído [a Suiza] el texto de César y en la medida que lo iba leyendo realmente tenía sueños, como alucinaciones en la noche. Ahí es que nacen esos dibujos, solo en blanco y negro [...] Me

30 salían así, no hacía tantos bocetos, me salían como una cosa extraña, rarísima”.

tronco hueco. Narowé la derribó y empezó a golpearla con un palo. Y la luna sonó, retumbó fuerte, lejos. Fue el primer manguaré de nuestra selva" (Calvo, 198-199)

10 Yo llevé a cabo esta entrevista en la ciudad de Lima. 
Como ya se había mencionado, Mariotti finalmente lleva a cabo seis grabados que representan diversas escenas, mitos y personajes de la narración, que aluden tanto a la cultura andina como a la amazónica. Incluye así al "Chullachaqui", "Los goces que ellas conciben", "Qoyllurite", "Otorongo", "Raymi Yawar" y "Tatuajes y cicatrices". Las imágenes se crean primero como pirografías, en blanco y negro, -que son las que se incluyen en el libro-y luego como serigrafías a color. Los dibujos creados por el artista tienen la particularidad de contar con líneas ininterrumpidas que construyen las composiciones: "Siempre tienen un inicio y un fin, pero sin interrupciones. Esto también se da muchísimo en algunas culturas e incluso algunos mantos sagrados están tejidos con un hilo sin nudos. Esta línea es evidente en 'Yawar Fiesta', 'Otorongo', 'Los goces que ellas conciben' y 'Tatuajes y cicatrices'”.

Dentro de la serie, Mariotti creó una representación del chullachaqui (fig. 2), el ser mítico que puede asumir cualquier forma humana y solo es reconocido por su pata de cabra o ciervo. "Un chullachaki es más, no el demonio del bosque, aquel espanto que las gentes creen, no. Un chullachaki es ídem que persona. Más es y menos es: apenas apariencia de persona" (Calvo Soriano, 34). Este chullachaqui muestra, desde una síntesis gráfica, un grupo de personajes con las mismas características - solo hechos de ojos, manos y piesque se repiten uno al lado del otro y, luego, en progresión hacia abajo. Hasta que la composición nos conduce a uno que muestra la pata diferente, que es, además, el único elemento que hace posible que se identifique como no-humano. Mariotti en este grabado desarrolla una síntesis del mito, que parece evocar formas de representación tradicionales de la Amazonía, como las líneas de los dibujos del kené. El artis- 
ta da forma al mito recordando composiciones propias del conocimiento tradicional amazónico. Las líneas también se podrían relacionar con la iconografía de ciertos tejidos de las culturas costeras precolombinas y, asimismo, el grupo de personajes en conjunto pareciera "constituir un manto" (Bendayán 2006, 62).

Luego de esta explicación del proceso de creación, compartido por Calvo y Mariotti, la pregunta que quedaría por resolver sería ¿Por qué Calvo tiene la necesidad de incluir los grabados y las fotografías en la novela? Tal vez suma este otro tipo de contenido para potenciar la relación de los personajes de ficción con los personajes reales de la cultura amazónica y las artes visuales de la región. Quizá tiene este imperativo de diálogo con otras artes, y con otros creadores, pues de esta manera construye una obra que no solo se asienta sobre un único soporte o lenguaje artístico. $\mathrm{O}$ incluso se da cuenta de la imposibilidad de evocar la realidad amazónica solo a través del lenguaje escrito, del discurso literario. Lo que es también importante de destacar es que este diálogo, iniciado por Calvo y desarrollado por Mariotti, permite la producción de una serie de grabados que representan imágenes que condensan una forma de pensar la Amazonía nutrida también por fuentes e imaginarios diversos que van desde lo precolombino hasta el arte más actual, como la propia novela.

\section{“Todo tiene relación con todo. Y más aquí, en la selva”}

Mientras Calvo se encuentra creando una novela a partir de los saberes de la medicina de la ayahuasca, otros artistas están trabajando en líneas de investigación similares. Una de ellas es la cineasta Nora de Izcue, quien en 1971 ya había llevado 
a cabo uno de los primeros registros documentales de una sesión de ayahuasca. En 1982, Nora se encuentra filmando en Iquitos su película "El viento del ayahuasca" cuando recibe la visita de César, quien llega a regalarle una edición de la novela. Es en este momento que ambos se dan cuenta de las coincidencias en sus intereses de trabajo, desde la literatura y el cine.

Nora de Izcue, la primera cineasta peruana, ha desarrollado una carrera cinematográfica sostenida por un trabajo comprometido de investigación y un lenguaje documental que tiene una fuerte presencia aún en sus proyectos de ficción. "La llegada de Nora de Izcue al cine se produce relativamente tarde. Teniendo poco más de treinta años, esta limeńa de clase alta, recién separada y con cinco hijos, se entrega a la posibilidad de construir su carrera profesional desde el audiovisual" ${ }^{11}$ (Cavalcanti, 94). A lo largo, de su trayectoria destaca la manera en la que explora en la representación de los personajes femeninos de contextos diversos. "Nora de Izcue se valió de enfoques muy diferentes para trabajar sus protagonistas femeninas [...] que se centran en un individuo pero también en representaciones colectivas enfocadas en el habla y el cuerpo [...] todas ellas son luchadoras, oprimidas y explotadas [...]" (Cavalcanti, 105). Esta cineasta peruana también es miembro fundadora de la Fundación del Nuevo Cine Latinoamericano. Es esta experiencia la que le permitió establecer un diálogo fructífero con otros creadores de América Latina que nutrió su experiencia como directora.

11 En el caso de las fuentes en portugués la traducción es mía. 
Justo al terminar sus estudios de cine con Armando Robles Godoy, De Izcue recibe el encargo de una filmación de sesiones de ayahuasca. El Dr. Oscar Ríos, psiquiatra peruano radicado en Canadá, le pidió que desarrollara un audiovisual que documentara las sesiones de un grupo de chamanes en Iquitos. La cineasta, aceptó el reto con cierto temor, pero también fascinada por lo que fue descubriendo durante su proceso de investigación. La grabación se llevó a cabo con película infrarroja de $16 \mathrm{~mm}$. De Izcue dirigió la grabación y Jorge Suárez se encargó de la cámara. Como ya se había mencionado, este trabajo representa uno de los primeros registros audiovisuales de este tipo de sesiones con la medicina de la ayahuasca.

Posteriormente, en 1982, De Izcue filma el largometraje "El viento del ayahuasca" (fig. 3). La película presenta una historia de amor sumergida en el contexto de las creencias mágico-religiosas de la Amazonía peruana. Miguel, un sociólogo limeño, conoce a Nexy una muchacha dominada por el temor a los yacurunas (seres del agua) y decide ayudarla y accede a ir donde un curandero. Así, se inicia la historia de cómo estos personajes se internan en la selva buscando profundizar en la curación en medio natural. Nexy es una mujer con una personalidad muy fuerte y no es representada, por De Izcue, como una víctima pasiva 34 de la sociedad o un personaje manejado por los hombres (Cavalcanti, 98).

Como ya se había explicado, mientras De Izcue se encuentra grabando la película en Iquitos, recibe la visita de su amigo César Calvo, quien llega para entregarle una copia de su recién publicada novela "Las tres mitades de Ino Moxo y otros brujos de la Amazonía" que le dedica de esta manera: "Para 
Norah, con la admiración creciente y el creciente carińo de su amazónico César. Iquitos en pleno viento del ayawashka, 82 ". De Izcue, cuenta que es en este momento en que ambos se dan cuenta de la coincidencia en sus temas de interés y de trabajo de sus más recientes proyectos: el conocimiento de la ayahuasca. Habían llegado por caminos de exploración e investigación muy diferentes, pero se habían encontrado en una búsqueda común.

Si se compara la novela de Calvo y el largometraje de De Izcue es posible identificar en ambos la necesidad del soporte documental relacionado con la ceremonia de la ayahuasca y el conocimiento en torno a esta planta enteógena. ${ }^{12}$ Por ejemplo, los dos recurren a maestros chamanes reales para construir y sostener sobre ellos sus ficciones, como el maestro Manuel Córdova, Don Hildebrando o Don José. Más allá de pensar las coincidencias del encuentro desde una dimensión solo personal, considero importante empezar a analizar cómo y por qué la investigación en torno a la medicina de la ayahuasca se convierte en un tema en el que confluyen creadores de diferentes especialidades - siendo Calvo y Nora solo dos casos de un vasto grupo- pues podría representar el punto de inicio de un lenguaje contemporáneo para el arte amazónico peruano, sostenido sobre una forma muy amazónica de entender la creación de conocimiento.

12 Desde 1979, se utiliza el término enteógena para referirse a las plantas reverenciadas por los pueblos. Su origen está en la raíz griega theos (dios), sumado al prefjio en (dentro) y al sufijo gen (que despierta o genera). Por lo tanto, significa "lo que genera dios en mî" (Eddowes, 23). 


\section{"El hilván invisible de las cosas"}

En los últimos años, la novela ha sido tomada como referente por algunos artistas visuales ${ }^{13}$ peruanos para generar proyectos inspirados en esta. Algunos de ellos han creado propuestas directamente como homenaje al escritor peruano y otros han decidido ilustrar pasajes de la narración de Calvo. Además, algunos han desarrollado líneas de trabajo más conceptuales -explorando en nuevos medios de representación- al destacar el valor del lenguaje y las miradas particulares sobre el conocimiento, tradiciones y saberes amazónicos. Estos proyectos diversos son muestra de la importancia de los diálogos entre arte contemporáneo y literatura para las prácticas artísticas peruanas en el siglo XX y XXI. También podríamos decir que son muestra del espectro que ha ido desplegando la novela, probando de alguna manera una de las frases enunciadas por el maestro Don Hildebrando: "Quien pronuncia palabras pone en movimiento potencias, desencadena otras fuerzas, otras palabras en el aire, sin ya nunca conocer su término. Poderes infinitos" (Calvo, 133).

Por ejemplo, Harry Chávez (Lima, 1978) crea en 2005 un autorretrato - "Yanapuma guerrero" (fig. 4) - que marca una relación muy personal con su lectura de la novela de Cal36 vo y su experiencia de curación con las plantas sagradas de la Amazonía. El mosaico, hecho de gemas de vidrio y mostacillas sobre mdf, muestra al protagonista acompañado de dos otorongos negros. Estos animales representan la fuerza

13 En este caso el ensayo no se incluyen las propuestas de artes escénicas y la performance que representan un nutrido grupo que considero necesitan un espacio independiente para el análisis. 
y el conocimiento de los maestros chamanes amazónicos, los guías durante los "viajes" con la medicina de la ayahuasca. Además, remiten a la figura del chamán mestizo Ino Moxo. De otro lado, Chávez plantea una imagen que cuenta con elementos de culturas precolombinas - como la pantera de dos cabezas de la cultura Paracas- y que desde su mirada también conectan con una gráfica pop.

Para el artista la pantera también representa el umbral de la muerte y el poder de la noche, conectado al conocimiento de las plantas maestras y el sentido de una misión. Chávez tiene un primer contacto con la novela en el inicio de su investigación personal sobre el conocimiento de la Amazonía:

"Todo mi acercamiento a la Amazonía empieza con la bús-
queda de una respuesta. Eso me motivó a leer a Carlos Cas-
tañeda e introducirme en el mundo chamánico y luego a
conectarme con el chamanismo selvático cuando leí a César
Calvo Soriano. Empecé a sentir fascinación y una curiosi-
dad tremenda por lo que decían. Conocí a gente que había
tenido experiencias con la ayahuasca, y yo mismo tuve un
encuentro con la medicina. Buscando una respuesta que le
diera sentido a mi vida descubrí este misterio muy perso-
nal" (Bendayán y Vidarte, 162).

El trabajo de Chávez nos muestra como los artistas contemporáneos continúan nutriendo sus proyectos de los conceptos desplegados en la novela y pueden construir una propuesta autobiográfica conectada a sus propios caminos de exploración en materiales y temáticas.

De otro lado, Nancy La Rosa (Lima, 1980) trabaja sobre la base de la novela, pero con una estrategia diferente. Su proyecto "Las pertenencias del aire" (2012 - 2018) (fig. 5, 6 y 7) está conformado por dos grabados, uno láser sobre triplay 
fenólico brasilero y otro gofrado en papel Hahnemüle. La artista copia sobre estos soportes el proemio de la novela. En este texto, como ya se había mencionado, Calvo describe una larga y detallada lista de elementos como aves, peces, animales, en general, y plantas que "suenan" cuando uno se encuentra en medio de la Amazonía. De esta manera, el escritor construye un espacio múltiple, con varias situaciones ocurriendo al mismo tiempo, y afirma su imposibilidad de abarcar la vastedad de esta región. Para La Rosa este texto contribuye en ayudarnos a entender que otras miradas sobre el mundo son posibles, especialmente desde el conocimiento y tradiciones de los pueblos originarios de la Amazonía.

Su trabajo al volver a copiar el texto del proemio, continúa una investigación concentrada en la manera en la que se han generado ciertos estereotipos sobre la Amazonía -iniciada en el caso de los pueblos en aislamiento y su representación en los medios-y la posibilidad de subvertirlos a través del arte:

"Hay discursos que se han podido sostener sobre la Amazonía por tanto tiempo que son sumamente nocivos, tanto para el espacio como para las personas que viven ahí. Cómo se puede construir un futuro si se está haciendo sobre una base discursiva que es absolutamente falsa y es creada a partir de intereses de hace décadas que en ningún momento tomaron en cuenta a la población. Algunas prácticas artísticas pueden ayudar a desmontar, por un lado, ese tipo de visiones $y$, por otro, brindar otras maneras para poder acercarnos a la Amazonía, sin tener todos estos prejuicios previos" (Bendayán y Vidarte, 39).

También en una línea de exploración de la construcción de otras formas de entender el conocimiento amazónico, a través del lenguaje de Calvo, Armando Andrade Tudela (Lima, 1975) en su serie "Mitades XXL" reúne textiles que evocan 
la forma de las cushmas - vestido tradicional de algunos pueblos amazónicos- pero en una escala sobredimensionada. La disposición de estas piezas en el espacio evoca un cuerpo presente y a la vez ausente, lo que también puede relacionarse con la representación de las dualidades o personajes "dobles" a lo largo de la novela. Las telas en el interior llevan inscripciones que forman algunas palabras relacionadas con el texto de Calvo y sus personajes, como ino moxo o el término oni xuma que tiene diversos significados, siendo uno de ellos "ayawashka". "Si yo pronuncio así, oni xuma, con la voz delgada, brillando, como deletreando hogueras y no letras, en lo oscuro, oni xuma significa filo-de-piedra-plana. Y dicha de otro modo significa tristeza-que-no-sale. Y significa punta-de-la-primera-flecha. Y significa 'herida', que a la vez significa labio-del-alma. Y siempre, al mismo tiempo, es ayawashka" (Calvo, 236).

Desde el soporte de la escultura, Rocío Rodrigo (Lima, 1960) en su trabajo titulado "Qero-Shipibo. Tres mitades de Ino Moxo" (2000) —en colaboración con la maestra Herlinda Hernández y Walter Canales- construye un objeto que representa un concepto propuesto por la novela, el del kero que conecta el conocimiento de la cultura andina y la cultura amazónica. La artista traslada a la pieza de madera las ideas que evoca la narración de Calvo. La figura del "quero" es mencionada a lo largo de la publicación y se ubica en las visiones del protagonista en medio de las sesiones con la medicina de la ayahuasca. Alrededor del quero los personajes se reúnen, meditan y convocan "las fuerzas que habitan el aire": "Le creí, no le creí. Pero cuando conocía a don Hildebrando, el Q'ero de Mank Kalli ocupaba el centro de su vivienda. Cuatro noches no reunimos en redor de ese Q'ero a meditar, a quedarnos callados convocando 
"las fuerzas que habitan el aire" para ponerlas al servicio "de nuestros hombres que padecen" (Calvo, 103). En este caso, sobre el vaso ceremonial de Rodrigo se encuentran los diseños shipibos del kené.

Finalmente, en la obra "Kaametza y Narowé"(2018) -llevada a cabo en acrílico sobre machetes de madera- Graciela Arias (Ayacucho, 1979) representa algunas escenas del mito amazónico de Kaametza [la muy hermosa] y Narowé [yo soy el que soy], parte de la narración de la novela de Calvo. Entre ellas destacan el enfrentamiento de Kaametza - la primera mujer - con el otorongo y la forma en que ella lo vence usando una de sus costillas como arma, costilla de la que luego nacerá Narowé - el primer hombre-. Además, Arias incluye el momento en el que Narowé derriba la luna con una flecha y la convierte en el primer manguaré. Esta artista, a su vez, hace uso del soporte de los machetes, figura muy simbólica de la vida en la Amazonía, ya que se trata de la herramienta que garantiza la subsistencia, pues con ella se puede cazar, abrir trocha, construir viviendas, entre otras actividades.

La narración, fundamental para la novela de Calvo, es tomada por la artista para construir nexos con sus propios intereses de trabajo. Arias recupera una narración mítica que inicia con una frase de la novela que destaca el lugar de la mujer en

40 el origen del conocimiento y la historia: "El primer hombre no fue hombre: fue mujer". Sobre la influencia de estas tradiciones amazónicas de los pueblos originarios Arias ha sabido construir un discurso propio relacionado con la representación de lo femenino, que le permite afirmar una crítica a las problemáticas sociales de la Amazonía contemporánea. La propia Arias lo explica de la siguiente manera: "Tratar el tema de la representación de lo femenino y el tema mitológico 
amazónico, me permiten sumar herramientas para manifestar los problemas que puedo ver en mi propio contexto, y levantar la voz frente a ellos" (Bendayán y Vidarte 2017, 69). De esta forma, su ilustración del mito también continúa su investigación sobre como la figura de la mujer amazónica se ha convertido en el agente contemporáneo capaz de unificar, contener y alimentar los saberes míticos del conocimiento amazónico. Al mismo tiempo, esa figura femenina parece encarnar a la propia Amazonía que para Arias "es la madre protectora y reproductora del bienestar" (Bendayán y Vidarte 2017,69$)$.

\section{Conclusión}

En resumen, en el presente trabajo se han revisado los diversos diálogos creativos que se han establecido desde "Las tres mitades de Ino Moxo y otros brujos de la Amazonía” de César Calvo en diferentes momentos de su creación, difusión y relectura más actual. Uno de los objetivos de este análisis ha sido reafirmar el valor de esta publicación como un aporte clave para los diálogos entre la literatura y las artes visuales, en el arte peruano. Además, desde este ensayo se ha propuesto que la novela de César Calvo - por su forma de comprender y afirmar los diálogos entre diversos medios y soportes artísticos- es muy importante para el desarrollo del lenguaje contemporáneo de las artes visuales en el Perú.

Primero, se analizó como, al incluir referencias a obras y artistas amazónicos del siglo XX, Calvo está construyendo de una manera muy particular el imaginario de su novela. Se revisó para eso los casos del pintor Calvo de Araújo, que influencia en la construcción de las imágenes que evoca la novela, y del 
artista Yando, que permite pensar en un enfoque compartido sobre las posibilidades de la representación amazónica peruana, a través del arte, en la segunda parte del siglo XX. Luego, se propuso el intercambio de Calvo y Nora de Izcue como un indicio que hace posible establecer un punto de inicio de un lenguaje contemporáneo para el arte amazónico peruano, sostenido sobre una forma muy amazónica de entender la creación de conocimiento. En última instancia, se han revisado los casos de las propuestas contemporáneas de Harry Chávez, Nancy La Rosa, Armando Andrade Tudela, Rocío Rodrigo y Graciela Arias, quienes reinterpretan desde el siglo XXI -y con metodologías de investigación y trabajo diversas - la novela de Calvo. La propuesta de este ensayo fue finalmente volver a la imagen de "las ideas que habitan el aire" para revisar la posibilidad de relectura constante de este conocimiento que todos compartimos, unas ideas que a todos nos pertenecen y que igual que "espíritus bondadosos, grandes, verdaderos, viven en el aire”, nos nutren y nos dan aliento.

Recibido: 18 de agosto del 2018.

Aprobado: 19 de diciembre del 2018. 


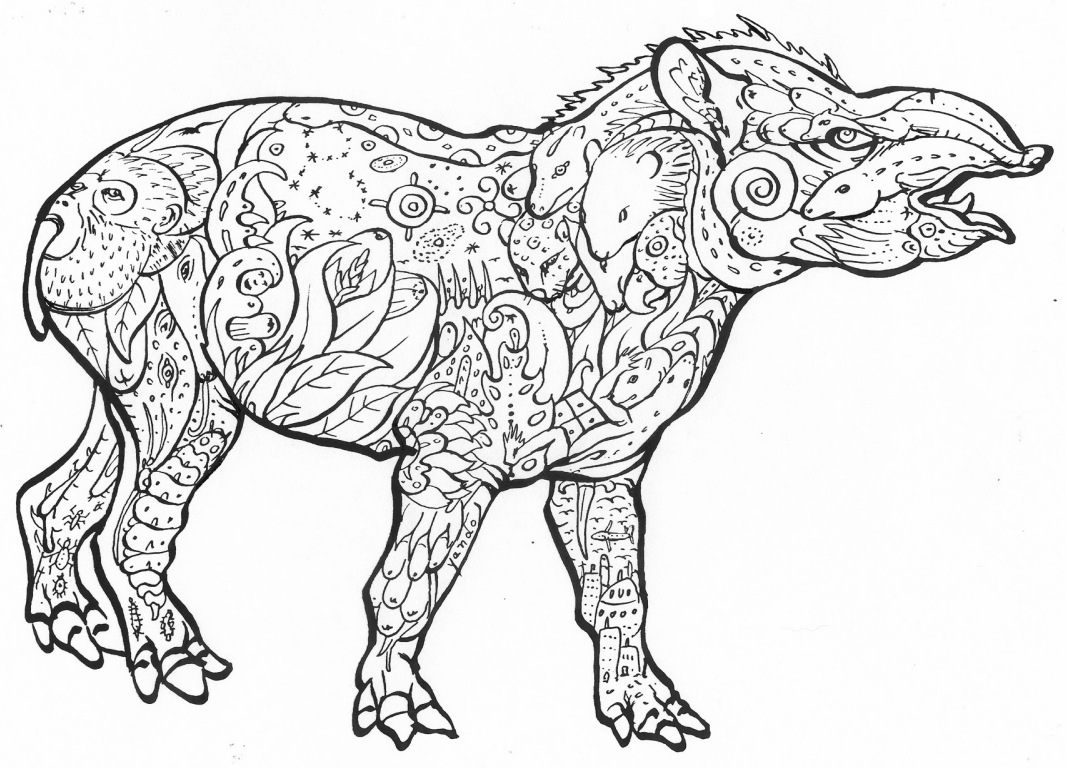

Fig. 1: Yando

Via láctea Manatí (1999) Dibujo a tinta y acrílico, impresión digital sobre papel de algodón. $43 \times 50 \mathrm{~cm}$ 
Las ideas que habitan el aire. Artistas en diálogo con las tres

mitades de Ino Moxo



Fig. 2: Francesco Mariotti

Chullachaqui. Serie Ino Moxo (1981)

Serigrafía sobre papel $67 \times 46 \mathrm{~cm}$ 




Fig. 3: Nora de Izcue

El viento del ayahuasca (1982)

Afiche de la película/ Diseño de Ana María Cillóniz

Archivo Nora de Izcue 
Las ideas que habitan el aire. Artistas en diálogo con las tres mitades de Ino Moxo

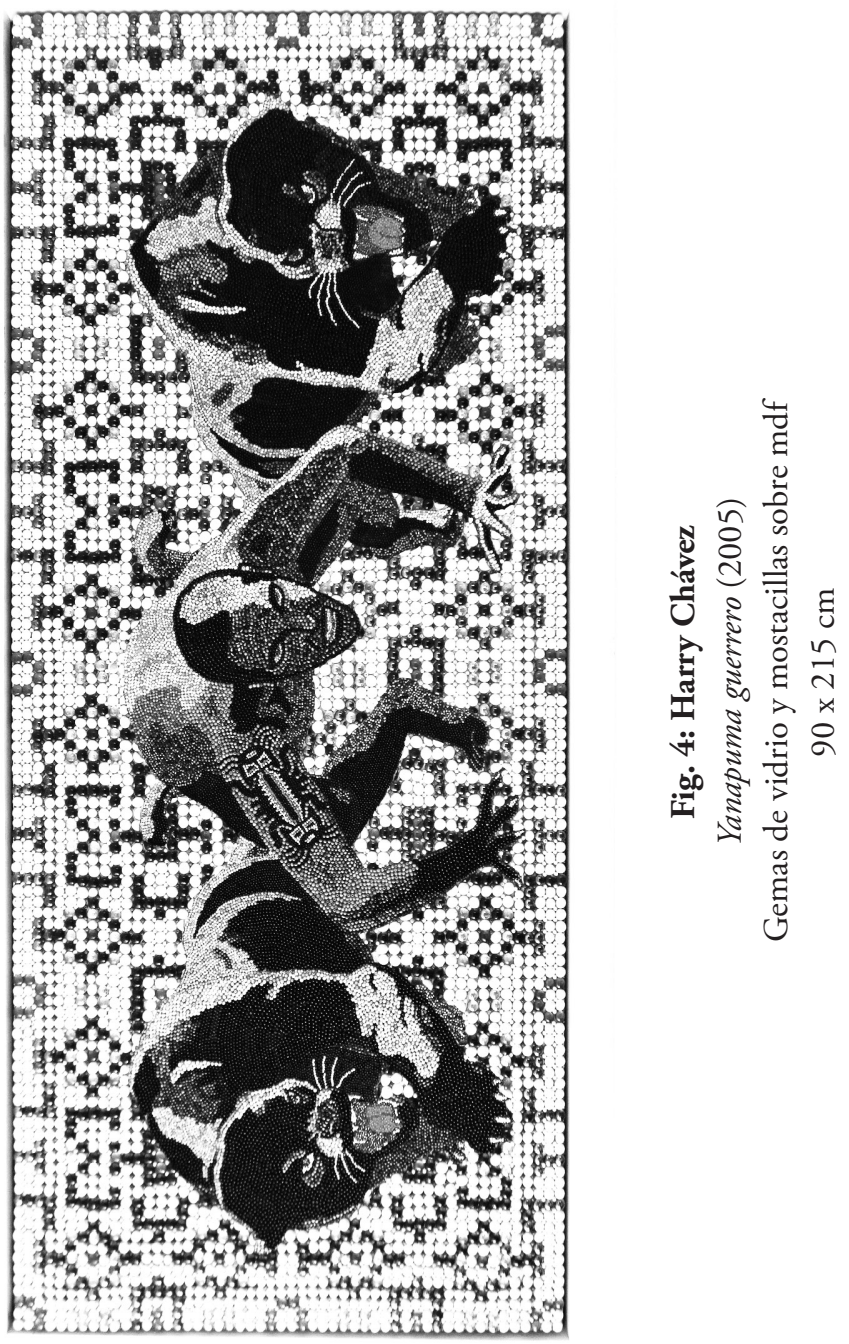




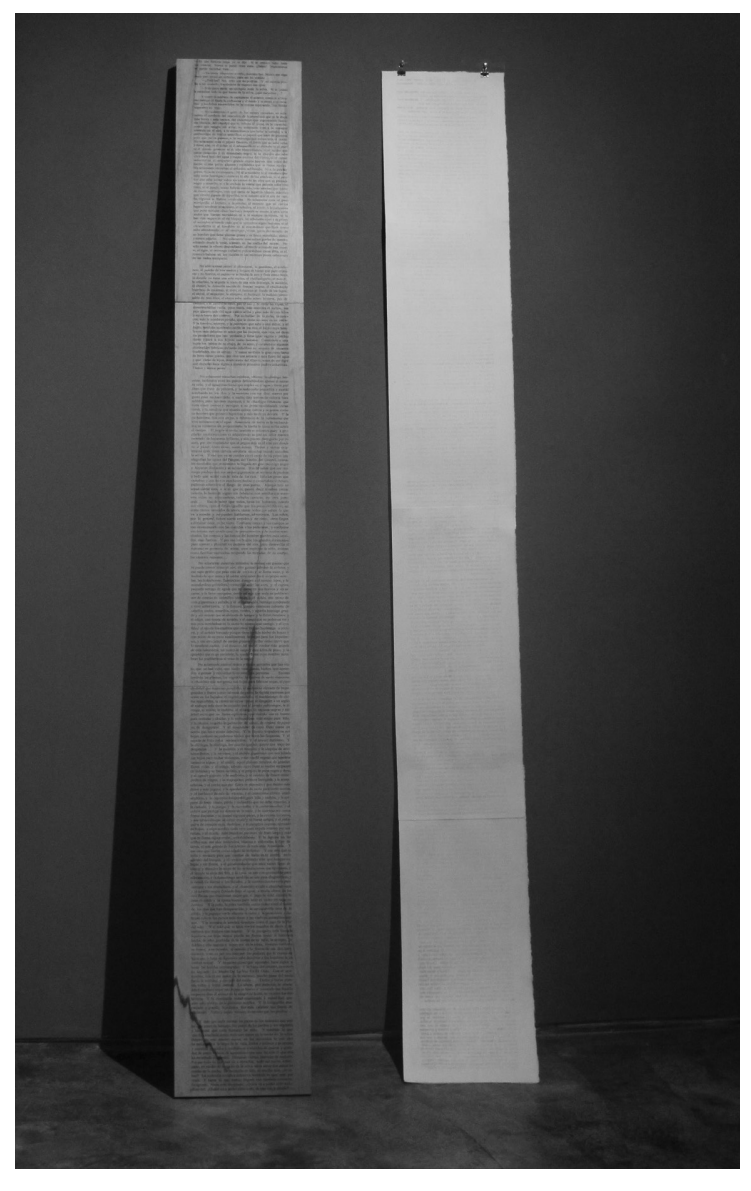

Fig. 5: Nancy La Rosa

Las pertenencias del aire (copia de exhibición) (2012 - 2018)

Grabado láser sobre triplay fenólico brasilero / 263.5 x $30 \mathrm{~cm}$.

Gofrado en papel Hahnemüle 265 g. / 290 x 30 cm. 
Las ideas que habitan el aire. Artistas en diálogo con las tres

mitades de Ino Moxo

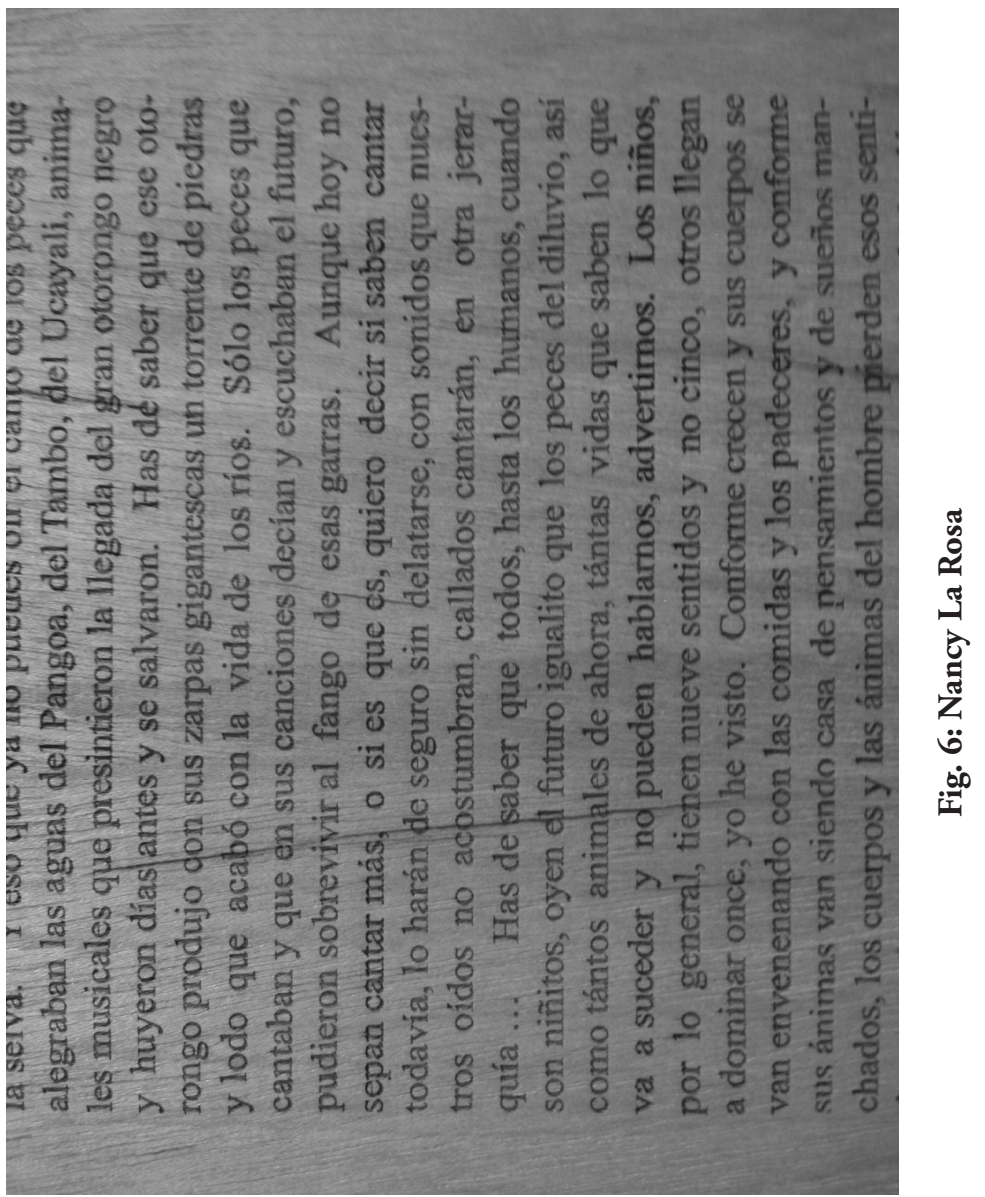

Revista del Instituto Riva-Agüero 







\section{Bibliografía}

Baca, Robert

(2017) "La sustancialidad del lenguaje amazónico. Heterogeneidad literaria y animismo en Las tres mitades de Ino Moxo y otros brujos de la Amazonía de César Calvo. En: Poétika 1. N² 2, agosto 2017, pp. 31-40.

Bendayán, Christian

(2006) La soga de los muertos: el conocer desconocido de la ayahuasca. Lima: Universidad Nacional Mayor de San Marcos.

Bendayán Christian y Alfredo Villar

(2013) Pintura amazónica: el milagro verde. Lima: Municipalidad de Magdalena del Mar.

Bendayán Christian y Alfredo Villar

(2015) "Calvo de Araújo. La leyenda del Amazonas”. En: Calvo de Araújo. La selva misma. Lima: Asociación Cultural Peruano Británica, pp 40-56.

Bendayán Christian y Giuliana Vidarte

(2017) Amazonistas. Lima: Bufeo. Amazonía+Arte e Infoartes del Ministerio de Cultura del Perú.

Calvo Soriano, César

2000 [1981] Las tres mitades de Ino Moxo y otros brujos de la Amazonía. Lima: Peisa.

Cavalcanti, Marina

(2017) "As protagonistas femininas nos filmes da cineasta peruana Nora de Izcue". En: Revista Extraprensa, 11(1), pp. 92-107.

Eddowes, John

(2005)

"Plantas sagradas del Perú: ¿Alucinógenos o enteógenos?”. En: Las Sumas Voces. Año 03, N 11, pp. 23.

Elguera, Christian

(2014) "Cosmopolítica del ayahuasca en 'Las tres mitades de Ino Moxo' de César Calvo”. En: Iquitos. Edición: Varón Consultores y Asociados. Lima: Telefónica del Perú, pp. 218-223. 
González Vigil, Ricardo

(2008) Años decisivos de la narrativa peruana. Lima: Editorial San Marcos.

Melis, Antonio

2000[1982] "Prólogo a la edición italiana. Las cuatro mitades de César Calvo y (del Perú)". En: Las tres mitades de Ino Moxo y otros brujos de la amazonía. Lima: Peisa.

Solórzano, Mónica

(2015) "César Calvo de Araújo. Maestro de la pintura amazónica”. En: Calvo de Araújo. La selva misma. Lima: Asociación Cultural Peruano Británica, pp. 18-22.

Vidarte, Giuliana

(2016) Un nuevo imaginario para la Amazonía peruana: la práctica artística de César Calvo de Araújo y Antonio Wong (1940-1965). Tesis de maestría en Historia del Arte. Lima: PUCP, Escuela de posgrado.

http://tesis.pucp.edu.pe/repositorio/handle/123456789/7755 
